\title{
Structural modifications in the mesophyll associated with cryopreservation of seven Hypericum species
}

\author{
D. STOYANOVA-KOLEVA ${ }^{1}$, M. STEFANOVA ${ }^{1 *}$, T.S. GANEVA $^{1}$, and E. ČELLÁROVÁ ${ }^{2}$ \\ Department of Botany, Faculty of Biology, Sofia University "St. KlimentOhridski”, BG-1164 Sofia, Bulgaria1 \\ Faculty of Science, Pavol Jozef Śafárik University in Košice, SK-04180 Košice, Slovakia ${ }^{2}$
}

\begin{abstract}
The present work examined seven Hypericum species (H. perforatum, H. humifusum, H. kalmianum, H. annulatum, $H$. tomentosum, $H$. pulchrum, and $H$. rumeliacum) produced in vitro and regenerated after cryopreservation. The aim of the study was to assess, by means of light microscopy (LM) and transmission electron microscopy (TEM), the effect of freezing temperature on leaf histological organization and mesophyll chloroplast ultrastructure. Histological analysis showed a negative effect of ultralow temperatures on leaf tissue structure in $H$. pulchrum and a positive effect in $H$. perforatum. The TEM analysis showed that chloroplasts from ultralow temperature treated $H$. annulatum, $H$. tomentosum, and $H$. rumeliacum had a typically structured internal membrane system without destruction of thylakoid membranes, however, those of $H$. humifusum had very high grana, and in $H$. perforatum, chloroplast thylakoid destruction occurred. The chloroplast internal membrane system of in vitro cultured control plants and in vitro cultured cryopreserved plants of $H$. kalmianum and $H$. pulchrum had a specific spatial orientation without any destruction of the membranes. The results show a specific response of each species to these experimental conditions.
\end{abstract}

Additional key words: chloroplast ultrastructure, in vitro culture, leaf histology.

\section{Introduction}

Cryopreservation is an up-to-date technique for a longterm conservation of plant genetic resources and plant tissues with valuable characteristics for a theoretically unlimited period of time (Reed 2008, Ozudogru et al. 2010, Pence 2014). Ultralow temperatures during cryopreservation have a direct effect on morphogenesis during subsequent regeneration (Kaczmarczyk et al. 2008). It is manifested in a collapse of photosynthetic tissue, in cell plasmolysis, and destruction of intracellular membranes (Danova et al. 2009, Ganeva et al. 2009). The success of this method is predetermined by the elimination of cell damage caused by freezing stress (Xu et al. 2006) in order to preserve cell vitality and genetic stability after thawing. Basically, research works with a cryopreserved plant material are aimed at elaborating an optimal protocol according to the requirements of a particular group of plants or valuable species. Many Hypericum species are medicinal plants (Yamaner et al.
2013), which makes them an appropriate object for cryoconservation. The most studied species is $H$. perforatum where plants regenerated after cryotreatment have been studied by physiological, biochemical, and genetic methods (Urbanová et al. 2002, 2006, Skyba et al. 2010). Subsequently, the research work has been extended over another Hypericum species (Petjová et al. 2014). Histological studies and ultrastructural studies of plastid apparatus of regenerated leaves should also be considered in the evaluation of lowtemperature effect and the regeneration potential of a species recovered after cryopreservation (Ganeva et al. 2009, Stoyanova-Koleva et al. 2013). The aim of the present study was to assess the effect of a freezing temperature on the leaf histological organization and mesophyll chloroplast ultrastructure in seven Hypericum species.

Submitted 9 December 2014, last revision 13 March 2015, accepted 31 March 2015.

Abbreviations: LM - light microscopy, TEM - transmission electron microscopy.

Acknowledgements: This work was supported by grants from the Bulgarian Ministry of Education, Youth and Science (DNTC/BGSK-01/2012) and from the Slovak Research and Development Agency (APVV SK-BG 0012-10). The paper was published with the financial support of project BG051PO001-3.3.06 - 0045 „Developing the capacity of specializing, postdoctoral and young scientist for teaching academic courses in and on a foreign language using current methodologies and ICT” funded by the Human Resources Development Operational Programme of the European Social Fund.

* Corresponding author, fax: (+35) 92 8656641, e-mail: mira_val@abv.bg

This article is published with open access at link.springer.com 


\section{Materials and methods}

Cryoprocedure and post-cryo regeneration were carried out in the Institute of Biology and Ecology, the Faculty of Science, P.J. Šafarik University in Košice, Slovakia (for details see Petjová et al. 2014), and plant material was kindly provided for structural analyses. Leaves from 35-d-old in vitro grown plants (control plants) and in vitro regenerated plants after cryo-treatment of shoot tips between -11 and $-4{ }^{\circ} \mathrm{C}$ (Petjová et al. 2014) (cryo-plants) from seven Hypericum species (H. perforatum L., $H$. humifusum L., H. kalmianum L., H. annulatum Moris, H. tomentosum L., H. pulchrum L., and $H$. rumeliacum Boiss.) were subjected to light microscope (LM) and transmission electron microscope (TEM) studies.

For structural analysis, 10 fully expanded leaves were taken from the $2^{\text {nd }}$ or $3^{\text {rd }}$ nodes of 5 plantlets of each species. Small segments from the middle part of the leaves were fixed in $3 \%(\mathrm{~m} / \mathrm{v})$ glutaraldehyde in a $0.1 \mathrm{M}$ sodium phosphate buffer ( $\mathrm{pH} \mathrm{7.4)}$ at $4{ }^{\circ} \mathrm{C}$ for $12 \mathrm{~h}$. For LM, handmade transverse cuttings were mounted on slides in glycerol. Histological observations and documentation of results were carried out by LM and a camera Nicon Eclipse 50i (Tokyo, Japan).

For TEM analysis, the leaf segments were post fixed in $1 \%(\mathrm{~m} / \mathrm{v}) \mathrm{KMnO}_{4}$ in the same buffer at room temperature for $2 \mathrm{~h}$. After dehydration by increasing concentrations of ethyl alcohol (from 25 to $100 \%$, v/v), the samples were embedded in Durcupan (Fluka, Buchs, Switzerland). Ultrathin cross sections were cut from the palisade parenchyma with a Reichert-Jung (Wien, Austria) ultramicrotome and contrasted with lead citrate (Reynolds 1963). Observation was performed by a JEOL 1200 EX (Tokyo, Japan) electron microscope.

\section{Results}

Histological analysis of the cryo-plants shows that six of the examined species - H. perforatum, $H$. annulatum, $H$. humifusum, $H$. kalmianum, $H$. rumeliacum, and $H$. pulchrum - had bifacial leaves (Figs $1 A-D$ and $2 A-H$ ) and only one species $-H$. tomentosum - had equifacial leaves (Fig. 1E,F). The leaf architecture of the control plants was the same. The bifacial leaves of the control plants consisted of one palisade layer, two to four spongy parenchyma layers, and adaxial and abaxial epidermes. The freezing temperature during the cryotreatment affected mainly the regeneration of photosynthetic tissues, and the effect depended on the species. The cryoplants from $H$. perforatum, $H$. annulatum, and H. tomentosum (Fig. $1 B, D, F$ ) developed leaves with a better structured mesophyll than the control plants (Fig. 1A,C,E). The leaf of the $H$. perforatum control plants was characterized by a regularly structured mesophyll (Fig. 1A), whereas the leaf mesophyll of the cryo-plants was almost two-fold thicker (Fig. 1B). In comparison with the control plants of $H$. annulatum (Fig. 1D), the palisade parenchyma in the cryo-plants of the same species had a more regular structure. It was composed of cylindrical elongated cells with a normal symplast contact area (Fig. 1C). The equifacial leaves of the control and cryo-plants from $H$. tomentosum had a bilaterally structured palisade parenchyma beneath both adaxial and abaxial epidermes, but in the cryo-plants, the morphological features of palisade cells were closer to the typical structure of this kind of tissue - cylindrical and elongated (Fig. 1E,F). Leaves from the H.humifusum, $H$. kalmianum, $H$. rumeliacum, and $H$. pulchrum control plants were bifacial with one-layer of palisade parenchyma and two to three layers of spongy parenchyma (Fig. 2A-H). The histological analysis of cryo-plants from $H$. humifusum, $H$. kalmianum, and $H$. rumeliacum shows that the ultralow temperature did not affect mesophyll structure (Fig. $2 A-F$ ). Only the epidermes of cryo-leaves from $H$. humifusum and H. rumeliacum consisted of larger cells (Fig. 2B,F), which increased the leaf blade thickness. In the present experimental conditions, the mesophyll in the control plants of only $H$. pulchrum represented a better structure than in the cryo-plants (Fig. $2 G, H$ ). In this species, the leaf mesophyll in the control plants was regularly organized (Fig. 2G). Although the cryotreatment did not affect the leaf architecture after regeneration, the cryoplants had irregularly structured mesophyll as well as pavement epidermal cells (Fig. $2 H$ ). The palisade cells were elongated but with wavy anticlinal walls which reduced the symplast contact between them. The upper tangential walls of the adaxial epidermal cells were concave.

The ultrastructural analysis of the plastid apparatus in newly formed leaves of the in vitro- and cryo-plants from the seven Hypericum species shows that the ultralow temperature affected the structure of the chloroplast internal membrane system in different ways. The cryoplants from $H$. annulatum, $H$. tomentosum, and H. rumeliacum regenerated leaves with well-structured plastids (Fig. 3B,D,F). The chloroplasts were lensshaped, the well-structured thylakoid membranes were parallel to the long axis, and uniformly distributed in the stroma. The internal membrane system consisted of relatively high grana (up to 30 thylakoids) connected with stromal thylakoids. The chloroplasts of both the control and cryo-plants from $H$. annulatum had about the same organization of the internal membrane system (Fig. 3A,B). The chloroplasts of the control plants possessed a well distinguished peristromium at the site of the cell wall and single starch grains (Fig. 3A). These features were not present in the chloroplasts of the cryoplants (Fig. $3 B$ ). In the plastids of the H. tomentosum and $H$. rumeliacum control plants, some morphological markers of thylakoid destruction were detected 
(Fig. 3C,E). The chloroplasts were round or irregularly shaped with an abnormal orientation of the internal membrane system. A fusion of the grana thylakoids and a fragmentation of the stromal thylakoids were observed. Large starch grains were visible in the stroma. Only in the mesophyll cells of the $H$. tomentosum control plants, the mitochondrial reticulum was observed. The mitochondria were amoeboid and formed a wide contact area with chloroplasts and peroxisomes (Fig. 3C). Destructive changes in the chloroplasts of the cryo-plants of $H$. tomentosum and $H$. rumeliacum were not detected (Fig. 2D,F).
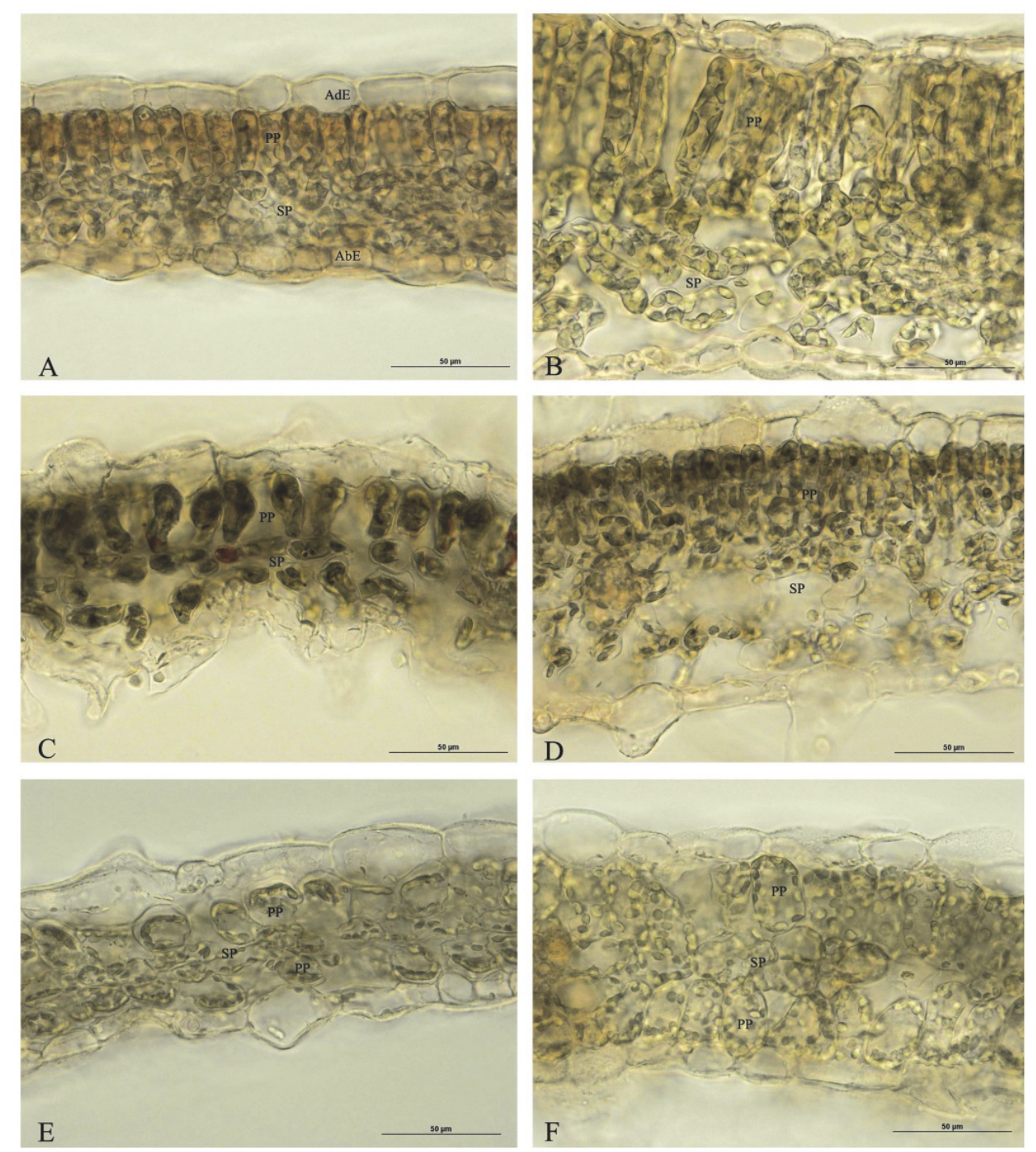

Fig. 1. Cross-sections of the leaf lamina of control plants $(A, C, E)$ and cryo-plants $(B, D, F)$ from $H$. perforatum $(A$ and $B)$, $H$. annulatum $(C$ and $D)$, and $H$. tomentosum $(E$ and $F)$. PP - palisade parenchyma, SP - spongy parenchyma, AdE - adaxial epidermis, $\mathrm{AbE}$ - abaxial epidermis; bars $=50 \mu \mathrm{m}$.

Another species in which substantial differences in the organization of plastids between the control and cryoplants were observed was $H$. humifusum (Fig. 4A,B). Chloroplasts in the control plants revealed signs of a severe destruction of thylakoid membranes (Fig. 4A) but the cryo-plants regenerated chloroplasts with a proper thylakoid organization (Fig. 4B). A unique feature only for this experimental variant was extremely high grana. Their height was almost equal to the transverse chloroplast section. In the $H$. perforatum control plants, chloroplasts had properly structured thylakoids, whereas the destruction of the internal chloroplast membranes was observed after the cryo-treatment (Fig. 4C,D). This was manifested in the fusion of granal thylakoids and the fragmentation of stromal thylakoid membranes. Two of the examined species $-H$. kalmianum and $H$. pulchrum formed chloroplasts with an atypical orientation of the internal membrane system both in vitro and after the cryo-treatment (Fig. 4E-H). The thylakoids were wavy or with a circular arrangement which is most noticeable in 
the chloroplasts of the $H$. pulchrum cryo-plants (Fig. 4H). For both species, this structural deviation did not correspond with destruction of the thylakoid membranes.

The study shows that four of the examined species $H$. annulatum, $H$. tomentosum, H. rumeliacum, and
H. perforatum - possessed starch grains in the stroma only in the control plants. In the chloroplasts of H. humifusum, H. kalmianum, and H. Pulchrum, starch was detected neither in the in vitro nor in cryo-plants.
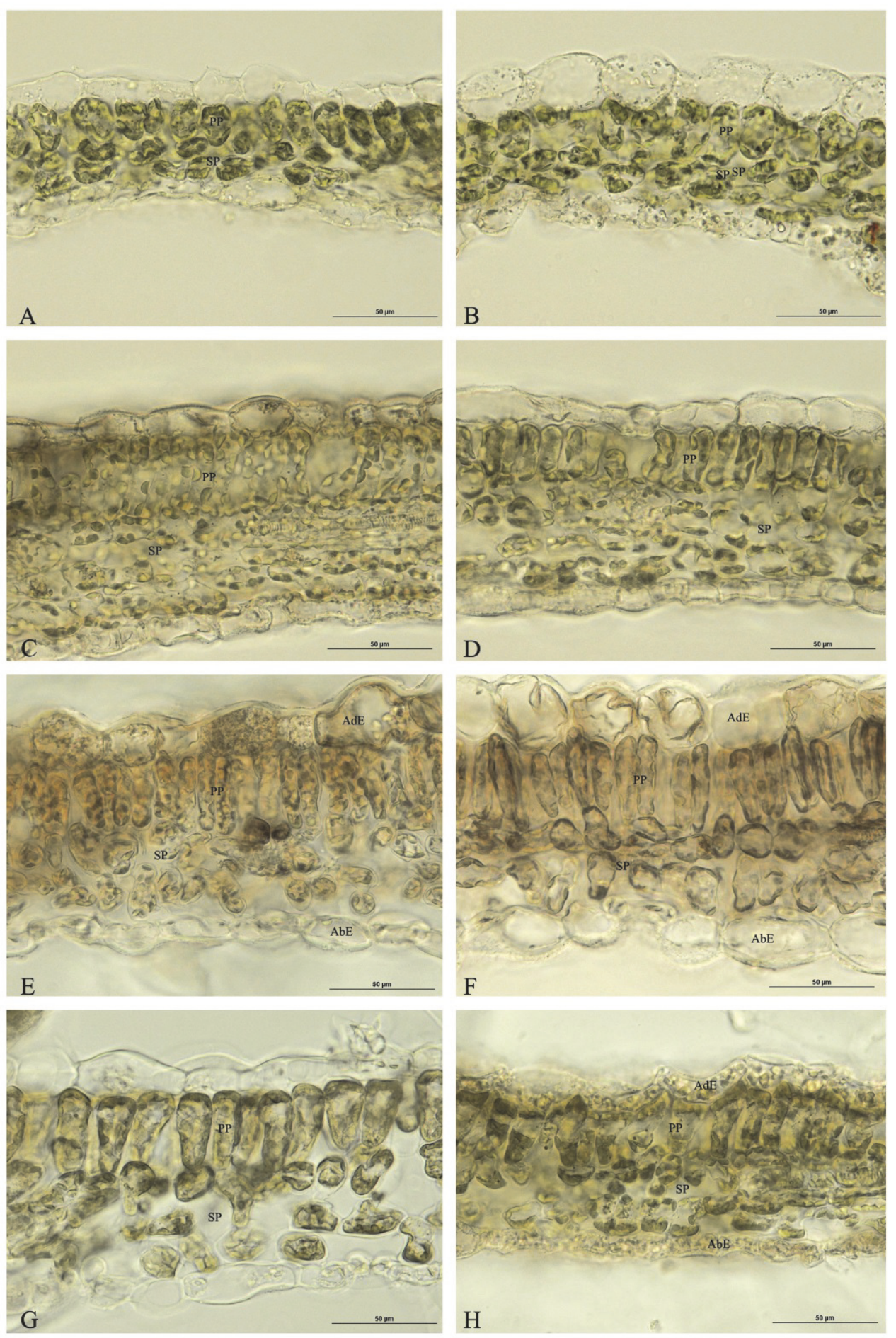

Fig. 2. Cross-sections of the leaf lamina of control plants $(A, C, E, G)$ and cryo-plants $(B, D, F, H)$ from $H$. humifusum $(A$ and $B)$, $H$. kalmianum $(C$ and $D)$, H. rumeliacum $(E$ and $F)$, and $H$. pulchrum $(G$ and $H)$. PP - palisade parenchyma, SP - spongy parenchyma, AdE - adaxial epidermis, AbE - abaxial epidermis; bars $=50 \mu \mathrm{m}$. 


\section{Discussion}

Ultralow temperature usually affects the morphogenesis of photosynthetic tissues and the formation of plastid apparatus during leaf regeneration. Cryopreservation is associated with a certain degree of dehydration and formation of ice crystals in cells and intercellular spaces (Samygin 1994). Also, it has been found out that ultralow temperatures can cause collapse of photosynthetic tissue (Danova et al. 2009, Ganeva et al. 2009), which could alter the shape of the cells. However, the histological analyses determined a negative effect of the ultralow temperature on the structure of leaf tissue in only one of the studied species (H. pulchrum). For this species, the new morphological characteristics of leaves regenerated after the cryo-treatment were mainly changes in the shape of photosynthetic cells and in contact between them. The negative effect of the cryo-treatment on the other six Hypericum species was insignificant. The $H$. perforatum cryo-plants which regenerated leaves with a better structured photosynthetic tissue in comparison with the

control plants during the current experiment deserve a particular attention. The registered morphological diversity in the leaf tissue organization in the cryo-plants probably correlated with different ecological characterristics of the examined Hypericum species. These species have a different origin and eco-morphological plasticity, and their cold resistance varies widely. This is the probable reason for the species-specific histological features of the cryo-plants. In this respect, Petjová et al. 2014 have sought a relationship between the tolerance to ultralow temperature and the post cryogenic recovery in 10 Hypericum species by means of morphological, physiological, and biochemical methods. During the current experiment, the histological analysis of the seven Hypericum species shows that only for $H$. pulchrum, the morphological characteristics of photosynthetic tissues could be a basis for optimization of the cryopreservation protocol.

The structure of plastid apparatus in plants
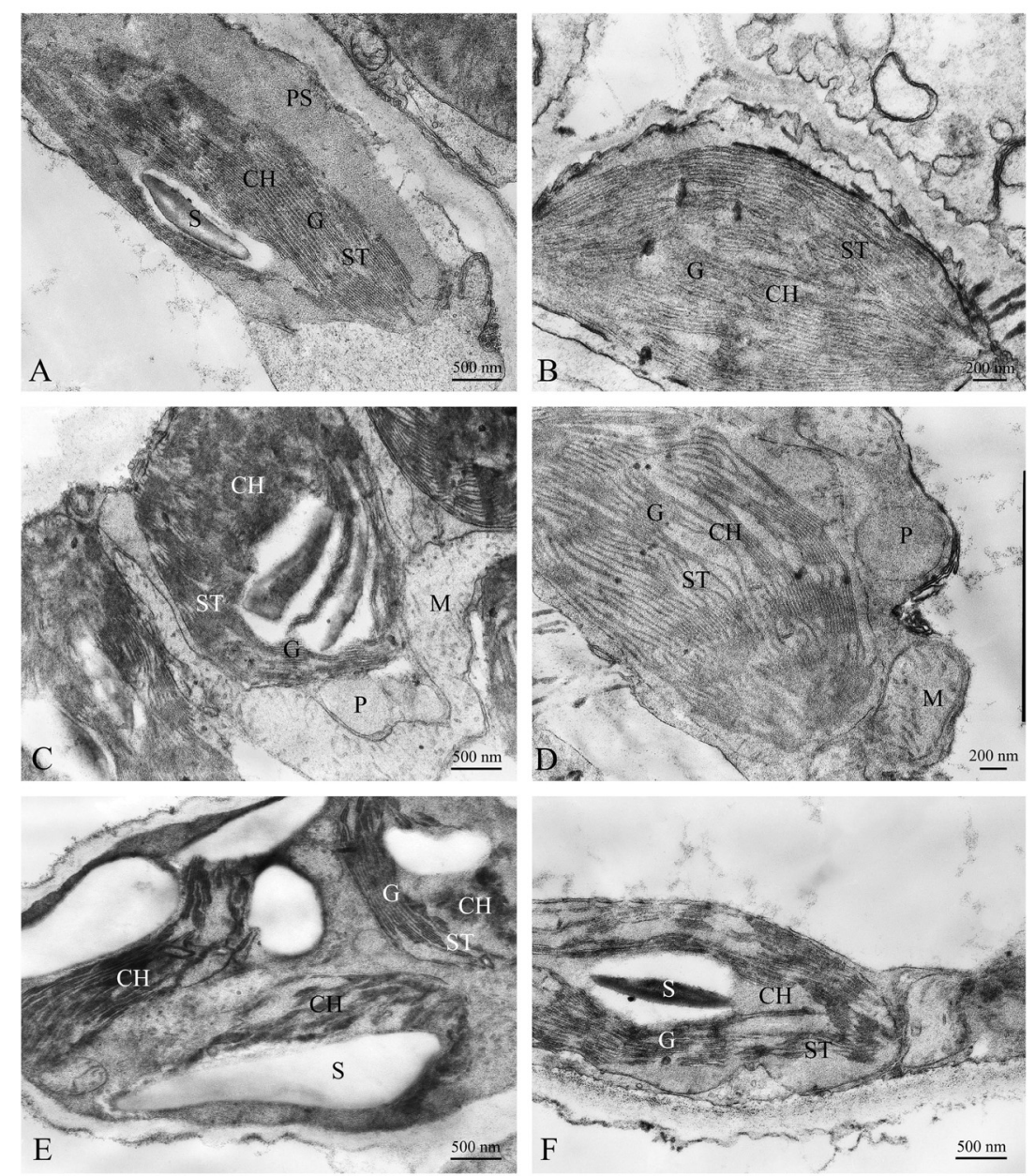

Fig. 3. Chloroplast ultrastructure of in vitro-plants $(A, C, E)$ and cryo-plants $(B, D, F)$ from $H$. annulatum $(A$ and $B)$, $H$. tomentosum $(C$ and $D)$, and $H$. rumeliacum $(E$ and $F)$. $\mathrm{CH}$ - chloroplast, $\mathrm{G}$ - granum, $\mathrm{M}$ - mitochondrion, $\mathrm{P}$ - peroxisome, PS - peristromium, $\mathrm{S}$ - starch, ST - stromal thylakoids; bars $=500 \mathrm{~nm}$ for $A, C, E, F$, bars $=200 \mathrm{~nm}$ for $B, D$. 
regenerated after cryo-treatment is an indicator of possible compensatory mechanisms to overcome an ultralow temperature stress at the subcellular level. The TEM analysis shows that chloroplasts in the cryo-plants from $H$. annulatum, $H$. tomentosum, and $H$. rumeliacum had a typically structured internal membrane system without any destruction of the thylakoid membranes. Obviously, these three species had a potential to overcome the ultralow temperature stress both at tissue and at subcellular levels of organization. The structural organization of plastid apparatus in $H$. humifusum is species-specific. Only in the leaves of the cryo-plants from this species, chloroplasts with very high grana (magnagrana) were formed. This structural transformation might compensate the effect of the ultralow temperature stress. Only in the $H$. perforatum cryo-plants, a partial chloroplast destruction was noticed (a reduction of only stromal thylakoids and partial fusion of grana). Obviously, in this Hypericum species, the negative effect of the cryo-treatment was compensated at the tissue but not at subcellular level. It has been found out that low temperature stress could cause a reduction of grana and swelling thylakoids (Kratsch and Wise 2000). During a low temperature, membranes are attacked by active
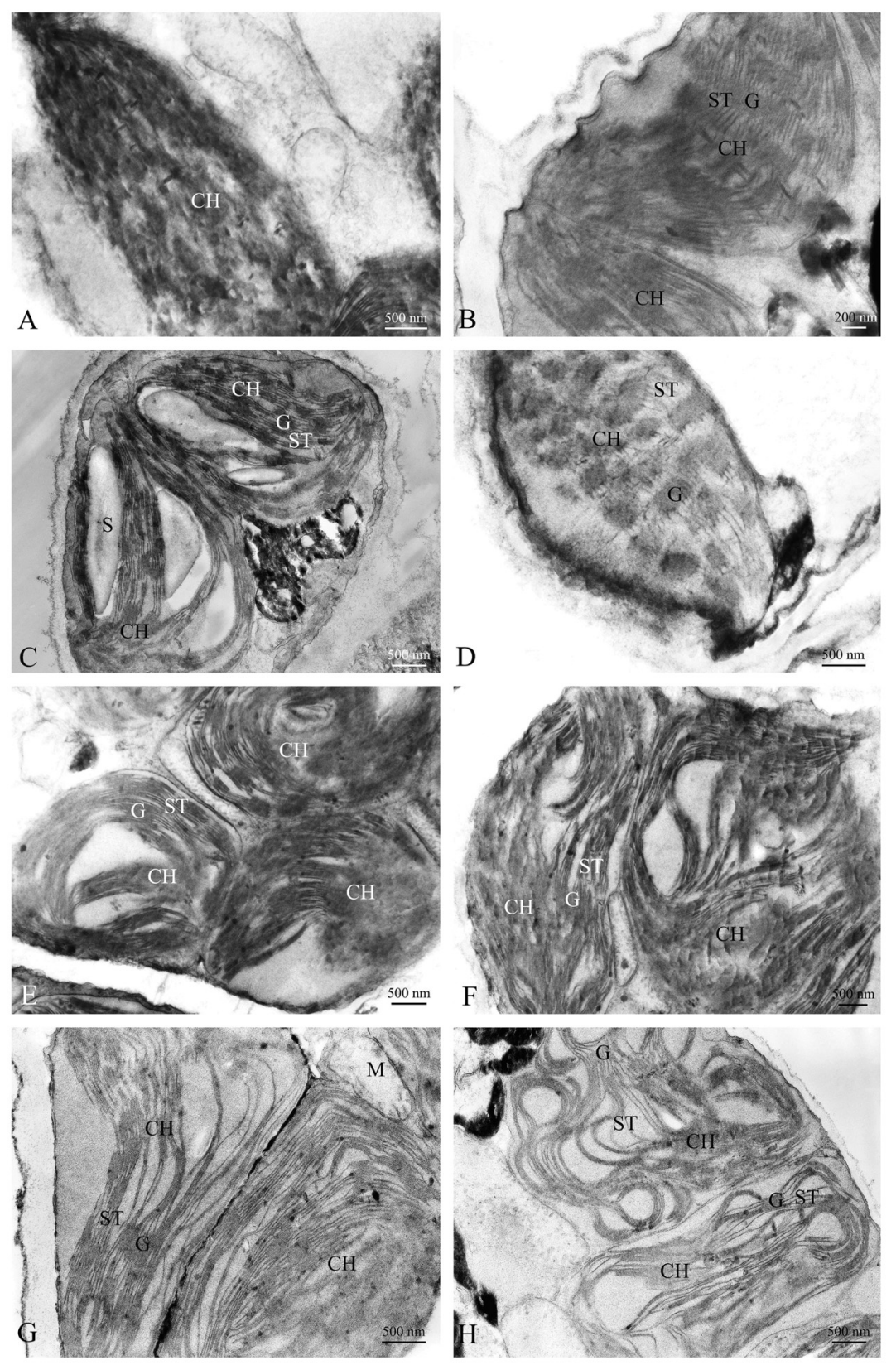

Fig. 4. Chloroplast ultrastructure of control plants $(A, C, E, G)$ and cryo-plants $(B, D, F, H)$ from $H$. humifusum $(A$ and $B)$, $H$. perforatum $(C$ and $D), H$. kalmianum $(E$ and $F$ ), and $H$. pulchrum $(G$ and $H)$. $\mathrm{CH}$ - chloroplast, $\mathrm{G}$ - granum, $\mathrm{M}$ - mitochondrion, $\mathrm{S}$ - starch, ST - stromal thylakoids. bars $=500 \mathrm{~nm}$ for $A, C, D, E, F, G, H$, a bar $=200 \mathrm{~nm}$ for $B$. 
oxygen forms, which finally lead to a structure damage (Suzuki and Mittler 2006). The organization of the chloroplast internal membrane system of the in vitro- and cryo-plants of $H$. kalmianum and $H$. pulchrum differed from the other species. Although the thylakoids were not arranged along the long axis of the chloroplasts, there were no signs of thylakoid membrane destruction. This specific chloroplast structure was not the only feature in common between H. kalmianum and H. pulchrum. Also, these are the two species which did not produce hypericin. It is not yet clear whether there is a relation between the structure of chloroplasts and the inability to synthesize hypericin.

In conclusion, each of the examined seven Hypericum species responded in different way to the cryo-treatment. Assimilation parenchyma in the $H$. perforatum cryoplants was structured evenly, but in the plastid apparatus, signs of grana fusion and stroma thylakoid rupture were visible. In the $H$. humifusum cryo-plants, the proper constitution of mesophyll and thylakoid membranes was observed. For this species, a specific feature was the extremely high grana. The $H$. kalmianum cryo-plants had an assimilation parenchyma with a regular organization but chloroplasts with atypically orientated thylakoid membranes. The cryo-plants from $H$. annulatum, $H$. tomentosum, and $H$. rumeliacum regenerated leaves with a well-structured assimilation parenchyma and chloroplasts. $H$. pulchrum was the only species whose cryo-plants had an impaired assimilative parenchyma accompanied by chloroplasts with a specific wavy internal membrane system. The results obtained in the complex structural study of seven Hypericum species show that, concerning genetically similar species, successful plant regeneration in vitro after a cryotreatment depends on the specific features of each species.

This article is distributed under the terms of the Creative Commons Attribution License which permits any use, distribution, and reproduction in any medium, provided the original author(s) and the source are credited.

\section{References}

Danova, K., Urbanová, M., Skyba, M., Čellárová, E., Stefanova, M., Koleva, D., Kapchina-Toteva, V.: Impact of cryopreservation on biochemical parameters of in vitro cultured Hypericum rumeliacum Boiss. - In: Niculita, P., Raspor, P., Silva, C.L.M., Popa, M.E. (ed.): Proceeding of the $2^{\text {nd }}$ International Symposium "New Research in Biotechnology". Pp. 78-85. USAMV, Bucharest 2009.

Ganeva, T., Stefanova, M., Čellárová, E., Uzunova, K., Koleva, D.: Structural responses of the photosynthetic apparatus of Orthosiphon stamineus Benth. to temperature stress after cryopreservation. - Bot. Serb. 33: 163-167, 2009.

Kaczmarczyk, A., Rutten, T., Melzer, M., Keller, E.R.J.: Ultrastructural changes associated with cryopreservation of potato (Solanum tuberosum L.) shoot tips. - CryoLetters 29: 145-156, 2008.

Kratsch, H.A., Wise, R.R.: The ultrastructure under chilling stress. - Plant Cell. Environ. 23: 337-350, 2000.

Ozudogru, E.A., Previati, A., Lambardi, M.: In vitro conservation and cryopreservation of ornamental plants. In: Jain, S.M., Ochatt, S.J. (ed.): Protocols for in Vitro Propagation of Ornamental Plants. Pp. 303-324. Humana Press, Totowa 2010.

Pence, V.C.: Tissue cryopreservation for plant conservation: potential and challenges. - Int. J. Plant. Sci. 175: 40-45, 2014.

Petjová, L., Bruňáková, K., Zámečnik, J., Zubrická, D., Mišianiková, A., Kimáková, K., Čellárová, E.: Relation between frost tolerance and post-cryogenic recovery in Hypericum spp. - CryoLetters 35: 171-179, 2014.

Reed, B.M.: Plant Cryopreservation: a Practical Guide. Springer, Corvallis 2008.

Reynolds, E.S.: The use of lead citrate at high $\mathrm{pH}$ as an electron-opaque stain in electron microscopy. - J. cell. Biol. 17: 208-212, 1963.

Samygin, G.A.: The processes responsible for plant cell damage by extracellular ice. - Russ. J. Plant Physiol. 41: 614-625, 1994.

Skyba, M., Urbanová, M., Kapchina-Toteva, V., Košuth, J., Harding, K., Čellárová, E.: Physiological, biochemical and molecular characteristics of cryopreserved Hypericum perforatum L. shoot tips. - CryoLetters 31: 249-260, 2010.

Stoyanova-Koleva, D., Stefanova, M., Čellárová, E., KapchinaToteva, V.: Chloroplast ultrastructure of Hypericum perforatum plants regenerated in vitro after cryopreservation. - Biol. Plant. 57: 793-796, 2013.

Suzuki, N., Mittler, R.: Reactive oxygen species and temperature stresses: a delicate balance between signaling and destruction. - Physiol. Plant. 126: 45-51, 2006.

Urbanová, M., Čellárová, E., Kimáková, K.: Chromosome number stability and mitotic activity of cryopreserved Hypericum perforatum L. meristems. - Plant Cell Rep. 20: 1082-1086, 2002.

Urbanová, M., Košuth, J., Čellárová, E.: Genetic and biochemical analysis of Hypericum perforatum L. plants regenerated after cryopreservation. - Plant Cell Rep. 25: 140-147, 2006.

Xu, X.-B., Cai, Z.-G., Gu, Q.-Q., Zhang, Q.-M.: Cell ultrastructure of kiwifruit (Actinidia chinensis) shoot tips during cryopreservation. - Agr. Sci. China 5: 587-590, 2006.

Yamaner, Ö., Erdağ, B., Gökbulut, C.: Stimulation of the production of hypericins in in vitro seedlings of Hypericuma denotrichum by some biotic elicitors. - Turk. J. Bot. 37: 153-159, 2013. 